\title{
The Kelvin versus the Raoult Term in the Köhler Equation
}

\author{
Heike Wex and Frank Stratmann \\ Leibniz Institute for Tropospheric Research, Leipzig, Germany \\ DAvid TopPing AND Gordon McFiggans \\ Centre for Atmospheric Sciences, University of Manchester, Manchester, United Kingdom
}

(Manuscript received 19 December 2007, in final form 6 June 2008)

\begin{abstract}
A comprehensive sensitivity study was carried out examining the sensitivity of hygroscopic growth and activation as modeled with the Köhler equation. Different parameters in the Köhler equation were varied within the range of their currently known uncertainties. The parameters examined include not only those describing the nature of the soluble substances in a particle/droplet and the surface tension $\sigma$ of the droplet solution, but also the recently proposed representation of parameters coupling the Raoult and Kelvin terms (i.e., partitioning of solute between the surface and bulk phases, although the recently proposed adsorption to wettable but insoluble material was not considered). The examined variations cause significant changes in both hygroscopic growth and activation. Whereas the hygroscopic growth regime below $95 \% \mathrm{RH}$ is insensitive toward the surface tension $\sigma, \sigma$ has a large influence on the activation, increasing with decreasing particle size. This implies that a cloud condensation nuclei $(\mathrm{CCN})$ closure, connecting particle hygroscopic growth to activation, has to account for an influence of the examined substance on $\sigma$ of the particle, especially for smaller particles in the size range from 50 to $100 \mathrm{~nm}$. A simple estimate showed that a lowering of $\sigma$ by only $10 \%$ can cause a change in the activated fraction (i.e., in the cloud droplet number concentration) of at least $10 \%-20 \%$. Where organic molecules are present in sufficient concentration to reduce $\sigma$, surface tension may be an important factor in determining the activation of aerosol particles to cloud droplets.
\end{abstract}

\section{Introduction}

During the last decade there has been an increasing intensity of research on the hygroscopic growth of atmospheric aerosol particles and on their activation to cloud droplets. This interest was driven by the need to increase our knowledge about the interaction of atmospheric aerosol particles with water vapor in the atmosphere. This is important with respect to two different aspects. First, this interaction determines the size of the particles at the relative humidities prevailing in the atmosphere and thus their direct effect on climate. Second, it also influences cloud properties by determining the concentration of cloud droplets, and with this cloud albedo and cloud lifetime (Twomey 1974; Albrecht 1989). Accordingly, research on hygroscopic growth

Corresponding author address: Heike Wex, Leibniz Institute for Tropospheric Research, Permoser Str. 15, 04318 Leipzig, Germany.

E-mail:wex@tropos.de and activation of atmospheric aerosol particles is needed to gain a better understanding of the earth's climate and of anthropogenic influences on climate change, processes in which clouds still present the single largest uncertainty (Forster et al. 2007).

Both hygroscopic growth and activation of atmospheric aerosol particles can be described by the Köhler equation, which connects the water vapor saturation above the surface of a droplet $S_{d}$ to the droplet diameter $d_{d}$. The Raoult term, also known as the water activity $a_{w}$, accounts for a lowering of $S_{d}$ due to soluble substance in the droplet. It approaches a value of 1 with increasing wet droplet size (for a fixed dry diameter of the aerosol particle) because of the increasing dilution of the solution. The Kelvin term describes the increase of $S_{d}$ due to the curvature of the droplet. It approaches a value of 1 with increasing droplet size, as the curvature decreases.

Many attempts have been made to derive the critical supersaturation for the activation of particles from their measured hygroscopic growth using Köhler theory, 
subsequently comparing the modeled and measured critical supersaturations. This constitutes a closure study for cloud condensation nuclei (CCN). Agreement between measured and modeled critical supersaturations increases the confidence in our understanding of the processes underlying the hygroscopic growth and activation.

$\mathrm{CCN}$ closure studies were done for both laboratory generated aerosol particles (e.g., Brechtel and Kreidenweis 2000a,b; Kreidenweis et al. 2005; Koehler et al. 2006; Svenningsson et al. 2006; Dinar et al. 2006b; Wex et al. 2007, hereafter WH07; Prenni et al. 2007) and atmospheric aerosol particles (e.g., Covert et al. 1998; Zhou et al. 2001; Dusek et al. 2003; Rissler et al. 2004; Ervens et al. 2007). In general, these closure studies were more often successful when particles were examined that consisted of well-known and understood (usually inorganic) substances (e.g., ammonium sulfate or sodium chloride), in contrast to the results obtained for less well-known (usually organic) substances [e.g., dicarboxylic acids, humic-like substances (HULIS), or secondary organic aerosols (SOAs)], mixtures of these, or atmospheric particles.

In laboratory studies introduced by Kreidenweis et al. (2005) and Svenningsson et al. (2006), reasons for the failure to achieve closure were ascribed to a possible existence of slightly soluble substances. Because hygroscopic growth often can only be measured up to $95 \%$ relative humidity $(\mathrm{RH})$, a possible change in dissociation with concentration or a decrease of the degree of nonideal behavior of the dissolved substances toward the more dilute solutions at higher RHs would not be detected by these hygroscopic growth measurements.

In summarizing CCN closure studies done for atmospheric aerosol, it was found that those studies that were able to achieve closure were generally not influenced by strong anthropogenic sources and had low concentrations of organic carbon in the aerosol phase (Broekhuizen et al. 2006). For studies that did not achieve closure, the discrepancy has generally been attributed to an incomplete understanding of the aerosol composition, especially the role of organic species (Stroud et al. 2007). Chang et al. (2007) compared measured $\mathrm{CCN}$ number concentrations with those derived with Köhler theory, using aerosol compositions obtained from aerosol mass spectrometer measurements as input. They found that during periods when the aerosol organic content is high, the predicted $\mathrm{CCN}$ number concentration was significantly lower than the measured one, and they identify surface tension and the unknown degree of internal mixing as possible reasons for this.

An increasing number of studies have focused on the surface tension of organic compounds and its influence on hygroscopic growth and activation. Facchini et al. $(1999,2000)$ described a reduction of the surface tension in atmospheric cloud and fog water samples and attributed it to polycarboxylic acids (which have molecular structures similar to HULIS) and to a lesser extent to mono- and dicarboxylic acids. It was estimated in Facchini et al. (1999) that surface tension lowering due to organic compounds has a potential effect on the earth's radiation budget comparable to that of droplet growth kinetics, solubility, and water-soluble gases.

Sorjamaa et al. (2004) and Sorjamaa and Laaksonen (2006) pointed out that surface active substances enrich at the particle/droplet surface and that an attributed change in the Raoult term also has to be accounted for.

In laboratory studies on particles as internal mixtures of certain inorganic and organic compounds, Henning et al. (2005) and Svenningsson et al. (2006) measured a surface tension lowering for the mixtures. Using these measured values in model calculations led to a good agreement between measured and modeled activation behavior for solution droplets in Henning et al. (2005). However, Svenningsson et al. (2006) stated that the modeled activation was very sensitive to the extrapolation of surface tension data from those concentrations where it was measured to those relevant during activation.

For atmospheric HULIS samples, surface tensions down to below $50 \mathrm{mN} \mathrm{m}^{-1}$ were measured (Kiss et al. 2005; Salma et al. 2006; Taraniuk et al. 2007), which is substantially lower than the value for water, $72.8 \mathrm{mN}$ $\mathrm{m}^{-1}$ (at $20^{\circ} \mathrm{C}$ ). However, these measurements were carried out in concentration ranges of up to $1 \mathrm{~g} \mathrm{~L}^{-1}$ which is about two to three orders of magnitude below those of HULIS particles that had grown to their equilibrium sizes at RHs ranging from $60 \%$ to $99 \%$, and about a factor of 20 to 100 below those of HULIS particles that are just activating.

Aerosol components have lower concentrations in rain and fog droplets than they have in hygroscopically grown or freshly activated particles/droplets, and therefore the measurements of surface tension on rain and fog water samples (e.g., Facchini et al. 2000) also give surface tension values that may be different from those that prevail during hygroscopic growth or activation.

In addition, measurements show that the reduction in surface tension builds up with time (Salma et al. 2006; Taraniuk et al. 2007). The time scales reported there for bulk solutions or large droplets (with sizes larger than several $100 \mu \mathrm{m}$ ) are on the order of seconds to minutes. But the process of activation proceeds on time scales that are much shorter. However, estimations proposed 
in Taraniuk et al. (2007) suggested that in the case of HULIS, the diffusion to the surface of a evolving droplet is sufficiently rapid to influence its surface tension, and with this the activation process.

Measurements on HULIS particles were done in Dinar et al. (2006b), WH07, and Ziese et al. (2008, hereafter ZW08), and a surface tension lowering had to be taken into account in these studies to accurately model the measured activation. However, the surface tension values that were needed to explain the measurements in WH07 and ZW08 were between 60 and $70 \mathrm{mN} \mathrm{m}^{-1}$, whereas $50 \mathrm{mN} \mathrm{m}^{-1}$ had been measured for a HULIS bulk solution.

Overall, the surface tension of aerosol particles that are at their equilibrium diameters or that are just activating cannot be assessed experimentally with up-todate methods. However, as this work will show, the surface tension does influence the activation of aerosol particles and thus will be important to account for when modeling the activation of aerosol particles to cloud droplets.

With respect to increasing our understanding of warm cloud droplet activation, McFiggans et al. (2006) generally outlined the effects of different physical and chemical aerosol properties on activation. With the study presented here, we give a comprehensive set of data on the sensitivity of the Köhler equation. We examine separately the sensitivity of the two parts of the Köhler equation, the Raoult and the Kelvin terms. For this, values of parameters of the Köhler equationnamely, those parameters that describe the soluble substance in a particle/droplet and the surface tension $\sigma_{s}$ of the droplet solution-are varied separately. This is done for two model substances, one more and one less hygroscopic, and for a range of dry particle sizes from 50 to $125 \mathrm{~nm}$. In this first step, constant values were used for $\sigma_{s}$, independent of the concentration.

An example of the effect of using $\sigma$ of water versus a concentration-dependent surface tension is given afterward. In addition, we explore the sensitivity to a recent representation of the partitioning of solvent molecules between the surface of a particle and the bulk interior. The aim is to determine the importance of different parameters in the Köhler equation and to get insight into possible explanations as to why $\mathrm{CCN}$ closure studies may or may not succeed.

\section{Köhler model}

The Köhler theory connects the equilibrium size of a hygroscopically grown solution droplet $d_{d}$ with the water vapor saturation at its surface $\left(S_{d}\right)$ :

$$
S_{d}=K a_{w}
$$

where $K$ is the Kelvin term and $a_{w}$ is the Raoult term or water activity.

The size of the solution droplet $d_{d}$ occurs explicitly in the Kelvin term, which accounts for the curvature of the droplets. This term also depends on the surface tension of the droplet $\sigma_{s}$. It is furthermore composed of the molecular weight of water $M_{w}$, the ideal gas constant $R$, the temperature $T$, and the density of water $\rho_{w}$ :

$$
K=\exp \left(4 M_{w} \sigma_{s} / R T \rho_{w} d_{d}\right) .
$$

Of these parameters, $\sigma_{s}$ is the most difficult to determine.

The second term of the Köhler equation, the Raoult term or water activity, can be obtained by different approaches; for example,

$$
a_{w}=\exp \left[-\left(\phi \nu n_{s}\right) / n_{w}\right]
$$

uses the number of moles of the solute and of water, $n_{s}$ and $n_{w}$, respectively, together with the osmotic coefficient $\phi$, and the number of ions per solute molecule $\nu$. The osmotic coefficient $\phi$ accounts for nonideal behavior in the solution, which is increasingly pronounced toward an increasing concentration of the solution. Therefore, $\phi$ may vary with the concentration of the solute in the droplet.

A series expansion of Eq. (3), omitting all but the linear term, yields the following (an approximation which also is used frequently):

$$
a_{w} \approx n_{w} /\left(\phi \nu n_{s}+n_{w}\right) \text {. }
$$

In both Eqs. (3) and (4), $\phi$ and $\nu$ sometimes are combined to produce a so-called van't Hoff factor $i$, which is then often used as a constant value over the whole range of different concentrations of the solute.

Another formulation of $a_{w}$ uses the mole fraction $X=n_{w} /\left(n_{s}+n_{w}\right)$ together with the activity coefficient $\gamma$, where $\gamma$ accounts for the nonideal behavior of the solution:

$$
a_{w}=\gamma X=\gamma\left[n_{w} /\left(n_{s}+n_{w}\right)\right]
$$

For all the above formulations of $a_{w}, n_{s}$ has to be known:

$$
n_{s}=\left(V_{s} \rho_{s}\right) / M_{s},
$$

including the solute density $\rho_{s}$, the molecular weight of the solute $M_{s}$, and the dry particle volume $V_{s}$; the latter being proportional to $d_{\mathrm{dry}}^{3}$, where $d_{\mathrm{dry}}$ is the dry particle diameter. However, for all of the above formulations of $a_{w}$, if the values for the properties of the chemical component or mixture of components that comprises $n_{s}$ are not known, the value of $a_{w}$ can only be estimated.

In an approach that was developed and applied in WH07, all the properties of the solute for which values were not known were combined into a single new parameter, $\rho_{\text {ion }}$. However, in $\mathrm{WH} 07, d_{\text {dry }}$ was known from 
TABLE 1. Properties of the more and less hygroscopic substances used in the sensitivity analysis (ammonium sulfate and HULIS). The nonideal behavior of ammonium sulfate was modeled following Pruppacher and Klett (1997). Values for HULIS were taken in accordance with WH07.

\begin{tabular}{|c|c|c|c|c|}
\hline & $\phi$ & $\nu$ & $\begin{array}{c}M_{s} \\
\left(\mathrm{~kg} \mathrm{~mol}^{-1}\right)\end{array}$ & $\begin{array}{c}\rho_{s} \\
\left(\mathrm{~kg} \mathrm{~m}^{-3}\right)\end{array}$ \\
\hline $\begin{array}{l}\text { More hygroscopic: } \\
\text { ammonium sulfate }\end{array}$ & $\begin{array}{l}\text { Non-ideal, } \\
\text { see caption }\end{array}$ & 3 & 0.132 & 1770 \\
\hline $\begin{array}{l}\text { Less hygroscopic: } \\
\text { HULIS }\end{array}$ & 1 & 1 & 0.3 & 1665 \\
\hline
\end{tabular}

measurements. The approach therefore was modified for this study to include a possible uncertainty in $d_{\mathrm{dry}}$. Thus, based on Eq. (3), $N_{\text {ion }}$ is defined as a measure for the number of ions (or molecules) of the soluble substance which are contained in the droplet solution:

$$
N_{\text {ion }}=\phi \nu n_{s}=\left(\phi \nu V_{s} \rho_{s}\right) / M_{s} .
$$

In the following, the sensitivity of the Köhler equation on variations in either $\sigma_{s}$ (i.e., in $K$ ) or in $N_{\text {ion }}$ (i.e., in $a_{w}$ ) will be derived and examined. The variations can be interpreted as uncertainties in the respective parameters, and the magnitude of the assumed variations (i.e., uncertainties) will be given in the next section.

\section{The model compounds}

This study examines the sensitivity of the Köhler equation for two different model compounds (i.e., for two different types of substances), one being more and one less hygroscopic. The substances chosen as the according model substances were ammonium sulfate and HULIS. The values which were used for the different particle properties are given in Table 1.

Ammonium sulfate is a well understood and abundantly occurring hydrophilic inorganic component of the atmospheric aerosol. It is known to show nonideal behavior. The upper panel of Fig. 1 shows $\phi$ for ammonium sulfate (Pruppacher and Klett 1997) and also, as a dotted line, the value that corresponds to a constant $i$ of 2.2 (using $\nu=3$ ). In the lower panel of Fig. 1, the deviation $[(i-\phi) / \phi]$ is given as a percentage.

In this study, Eq. (3) was used to determine $a_{w}$; in calculations for ammonium sulfate, the variation of $\phi$ was accounted for following Pruppacher and Klett (1997), as shown in Fig. 1. Calculations done for this study were compared to those from a more elaborate model (Topping et al. 2005a,b, 2007) for ammonium sulfate. Figure 2 shows the good agreement between these two formulations, with differences in the subsaturated regime being $<2.5 \mathrm{~nm}$ at any saturation. The criti-

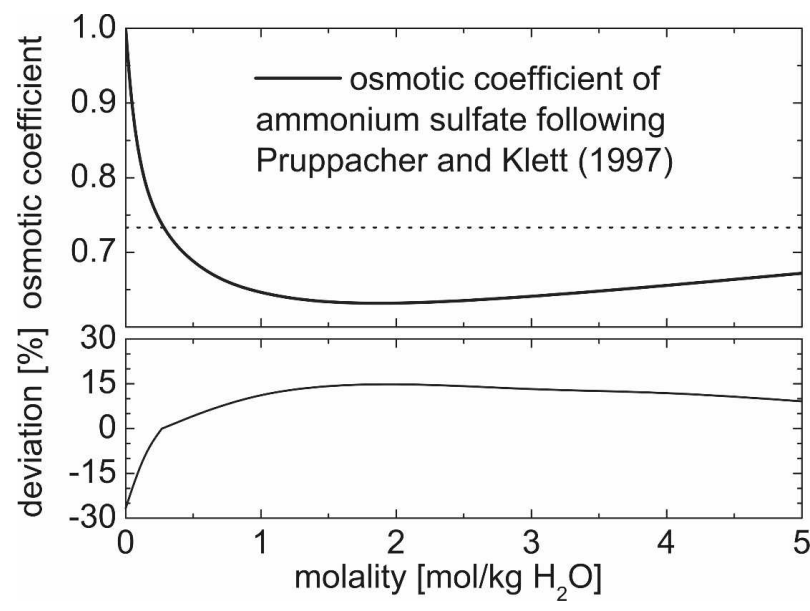

FIG. 1. (top) The osmotic coefficient, following Pruppacher and Klett (1997). The dotted line indicates the value of 0.733 , which, together with $\nu=3$, corresponds to a constant $i$ of 2.2. (bottom) The deviation between this constant value and the varying osmotic coefficient, given as a percentage.

cal supersaturations for the two formulations are $0.43 \%$ and $0.45 \%$ for the model by Topping et al. (2007) and the one used here, respectively.

Values of the properties of the second model substance were chosen according to those found for HULIS in WH07. HULIS is a generic term for large organic molecules found in the atmospheric aerosol. HULIS shows a lower hygroscopicity than ammonium sulfate and is less well understood. HULIS sampled and extracted from different atmospheric aerosol samples worldwide shows a span in values determined for its properties: reported molecular weight ranges from 200 to 700 atomic mass units (amu) (Kiss et al. 2003; Dinar et al. 2006b; Samburova et al. 2005), and density values

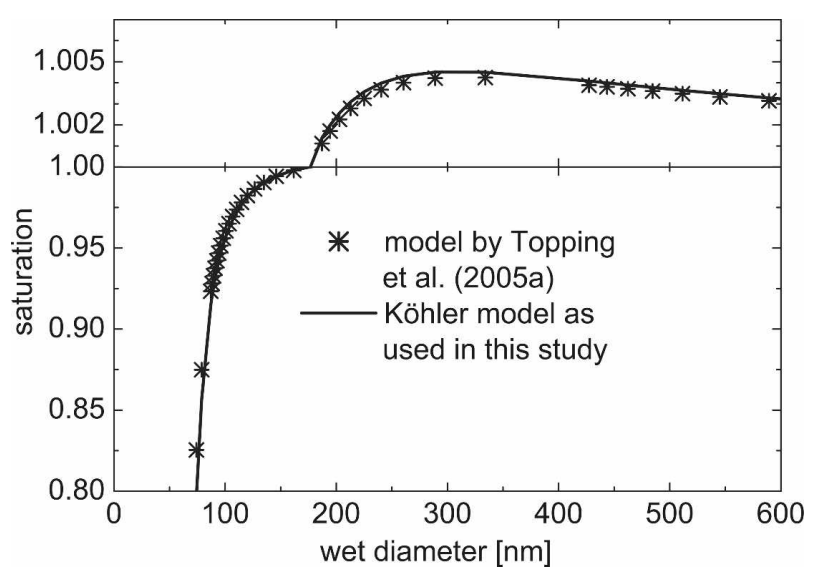

FIG. 2. A comparison of the Koehler curves for an ammonium sulfate particle with a dry diameter of $50 \mathrm{~nm}$ from the model of Topping et al. (2005a) and from the model used in this study. 
between 1.5 and $1.7 \mathrm{~g} \mathrm{~cm}^{-3}$ were given (Hoffer et al. 2006; Dinar et al. 2006a). The values for the HULIS properties used here are within the range of values reported in literature. Because of a general lack of knowledge about HULIS (and in contrast to the treatment of ammonium sulfate), ideal behavior and no dissociation of the molecules in solution were assumed. It has to be added that HULIS has an influence on hygroscopic growth and activation of atmospheric aerosols not only through its hygroscopic behavior but also through a possible influence on $\sigma_{s}$. Equilibrium values for $\sigma_{s}$ as low as $50 \mathrm{mN} \mathrm{m}^{-1}$ have been measured (Salma et al. 2006; Kiss et al. 2005; Taraniuk et al. 2007). However, the influence of HULIS on the $\sigma_{s}$ of an activating droplet is still under scientific debate (e.g., Kokkola et al. 2006; WH07; ZW08).

Of the parameters determining $K, \sigma_{s}$ is the one whose value is the most difficult to determine. For $a_{w}$, the parameters whose values can be difficult to determine are those describing the soluble substance, especially when less well characterized substances or mixtures (as in the case of atmospheric aerosols) are to be dealt with. In Eq. (7), all these parameters were combined into $N_{\text {ion }}$. Overall, for the sensitivity study presented here, $\sigma_{s}$ and $N_{\text {ion }}$-the former determining $K$; that latter being important for $a_{w}$-were the parameters that were varied.

For $\sigma_{s}$, values between that of water $\left(72.8 \mathrm{mN} \mathrm{m}^{-1}\right.$; Low 1969) and a value $30 \%$ lower $\left(51 \mathrm{mN} \mathrm{m}^{-1}\right)$ were considered. This is within the range that was measured for atmospheric HULIS, as cited above. To obtain a general idea of the sensitivity to a variation of $\sigma_{s}$, this variation was examined for both model compounds. The surface tension of a droplet can also depend on the concentration of the dissolved substance, as already described by Szyszkowski (1908). ZW08 found a concentration-dependent surface tension for HULIS particles from a combination of measurements and model calculations (see Fig. 3). The concentration range that roughly limits the activation regime for the HULIS particles is indicated as a hatched area in Fig. 3. Stars in Fig. 3 indicate the surface tensions at which particles with dry diameters of 50, 75, 100, and $125 \mathrm{~nm}$ activate. In Fig. 3, all of the indicated surface tensions relevant for activation are above $60 \mathrm{mN} \mathrm{m}^{-1}$. A lowering of $\sigma_{s}$ up to $30 \%$ indicates the larger end of a possible shift in $\sigma_{s}$. The sensitivities derived in this work relate to a $1 \%$ shift in the examined parameter, and a maximum variation of $30 \%$ was chosen to cover the whole range of experimentally observed values. The sensitivities of the Köhler equation that will be derived in the following sections will subsequently be applied to the two HULIS

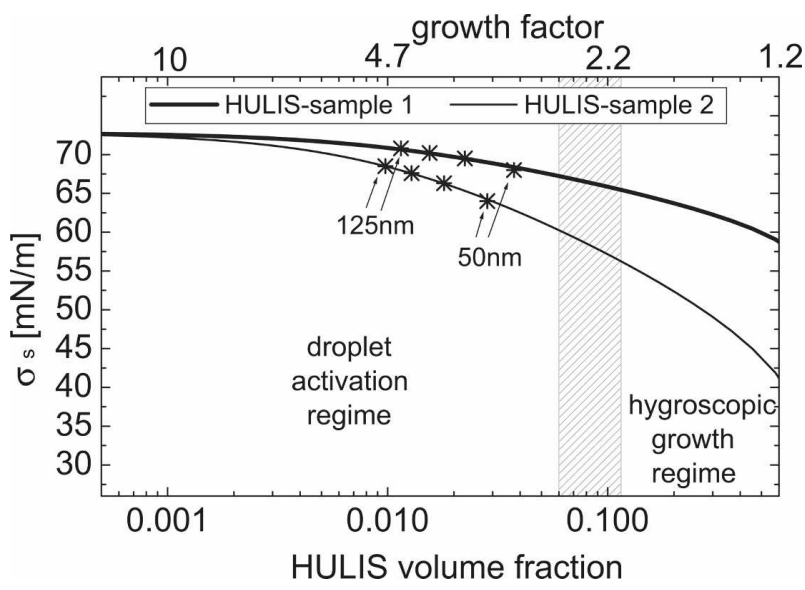

FIG. 3. Values for a concentration-dependent $\sigma_{s}$ for two different HULIS samples, based on a parameterization of measured hygroscopic growth and activation given in ZW08. The dotted line roughly divides the concentration range in a hygroscopic growth and an activation regime.

samples introduced in Fig. 3, including the concentration-dependent treatment of $\sigma_{s}$.

The parameter $N_{\text {ion }}$ was varied in a range from $-30 \%$ to $+30 \%$ of the starting value. As can be seen from the definition of $N_{\text {ion }}$ in Eq. (7), a variation of $N_{\text {ion }}$ can be viewed as a simulation of an uncertainty in the number of molecules or ions contained in the droplet. This, in turn, can be attributed to an uncertainty in any of the parameters included in $N_{\text {ion }}$, namely, the solute properties $\phi, \nu, V_{s}, \rho_{s}$, and $M_{s}$. Here, a statement that was explored in Dusek et al. (2006) becomes obvious. The dry particle diameter $d_{\text {dry }}$ is related to $V_{s}$ via

$$
V_{s}=\left(\pi d_{\text {dry }}^{3}\right) / 6 .
$$

This gives $d_{\mathrm{dry}}$ an important role in the determination of $N_{\text {ion }}$ because, unlike the other solute parameters that enter $N_{\text {ion }}$ linearly, a variation in $d_{\mathrm{dry}}$ influences $N_{\text {ion }}$ to the third power. For this study, a maximum deviation of $30 \%$ in $N_{\text {ion }}$ was chosen because it can already be caused by omitting the nonideal behavior of a substance (see Fig. 1) or, equally, by a deviation of the dry diameter of the particle by $9 \%$.

\section{Variations}

When looking at Eqs. (2) and (3) for the Kelvin term and the Raoult term, respectively, it can be seen that the Raoult term is dominant for smaller $d_{d}$ whereas the Kelvin term is the dominant term at larger values of $d_{d}$, with both terms acting in opposite directions. This is due to the $-d_{d}^{-3}$ versus the $d_{d}^{-1}$ dependency of the Raoult and Kelvin term, respectively. The maximum in 


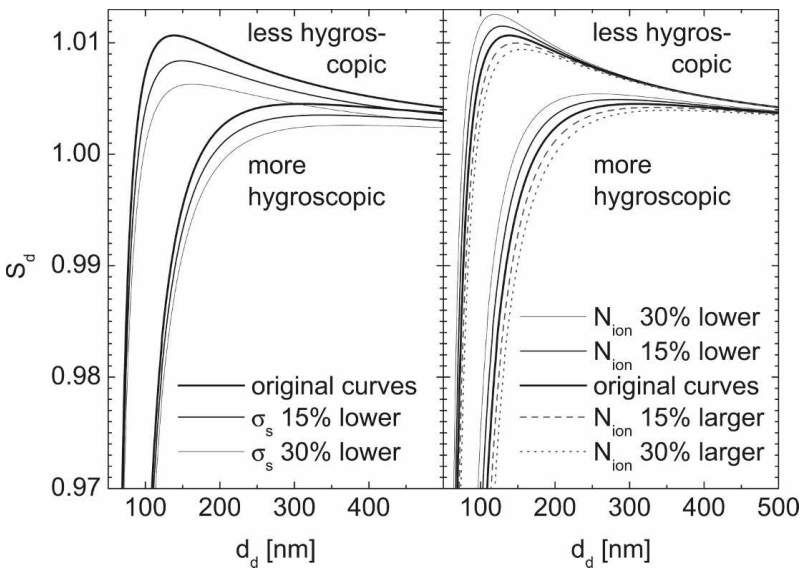

FIG. 4. Different combinations of $K$ and $a_{w}$, yielding different Koehler curves: (left) variations in $\sigma_{s}$ for fixed values of $N_{\text {ion }}$ for the two different substances; (right) varying values of $N_{\text {ion }}$ for a constant $\sigma_{s}$.

the Köhler curve denotes the critical size and critical supersaturation $S_{\text {crit }}\left(S_{\text {crit }}=S_{d}-1\right)$ at which a particle activates to become a cloud droplet. Figure 4 shows Köhler curves for a dry particle size of $50 \mathrm{~nm}$ for the two model substances. To obtain these curves, $K$ and $a_{w}$ were determined for different values of $\sigma_{s}$ and $N_{\text {ion }}$ varying around the values given in Table 1 . Both a change in $a_{w}$ with constant $K$ and a change in $K$ with constant $a_{w}$ produce different Köhler curves with different maxima (i.e., with different $S_{\text {crit }}$ ) but also with different values for $d_{d}$ at any fixed saturation. Comparing the left and right panels of Fig. 4, it can be seen already that a variation in $\sigma_{s}$ gives rise to larger changes in $S_{\text {crit }}$ than an equally large variation in $N_{\text {ion }}$. The opposite occurs when looking at $d_{d}$.

The curves in Fig. 5 show values of $d_{d}$ at fixed saturations for different variations of $N_{\text {ion }}$ (top) or $\sigma_{s}$ (bottom). The values in Fig. 5 were taken from the curves of the less hygroscopic compound as given in the left panel of Fig. 4. The slope of each of the curves in Fig. 5 is equal to the derivative of $d_{d}$ with respect to $N_{\text {ion }}$ or $\sigma_{s}$. The slope of the curves increases for increasing saturations, indicating that the sensitivity of $d_{d}$ to changes in $N_{\text {ion }}$ and $\sigma_{s}$ increases toward larger saturations.

A change of $S_{\text {crit }}$ with respect to a variation in either $\sigma_{s}$ or in $N_{\text {ion }}$ is shown in Fig. 6. Again, the slopes of the two curves in Fig. 6 indicate the derivatives of $S_{\text {crit }}$ with respect to $N_{\text {ion }}$ or $\sigma_{s}$. A larger dependence of $S_{\text {crit }}$ on $\sigma_{s}$ than on $N_{\text {ion }}$ can be seen.

\section{Sensitivities}

Figures 5 and 6 show results for particles with a dry diameter of $50 \mathrm{~nm}$ for the less hygroscopic model sub- variation from the original value of $\mathrm{N}_{\text {ion }}$ in $\%$

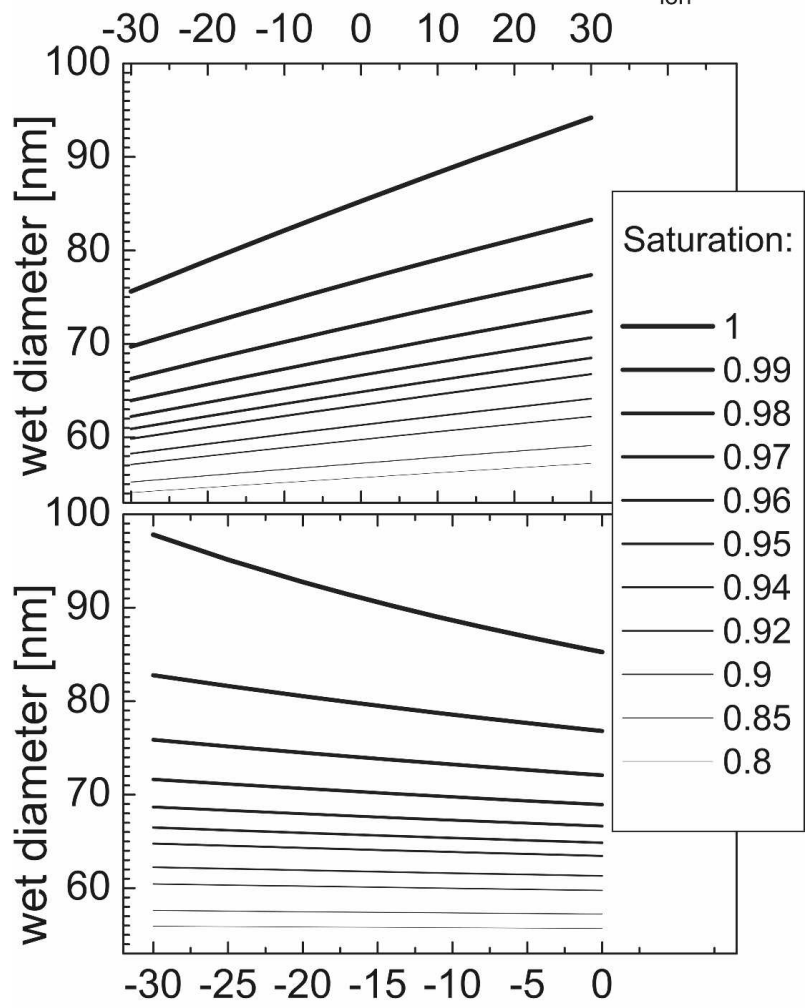

\section{variation from the original value of $\sigma_{\mathrm{s}}$ in \%}

FIG. 5. Values of the wet diameters $d_{d}$ at fixed saturations for different variations of (top) $N_{\text {ion }}$ and (bottom) $\sigma_{s}$ for particles with a dry diameter of $50 \mathrm{~nm}$ (consisting of the less hygroscopic model substance).

stances only. The slopes of the curves shown in Figs. 5 and 6 give the sensitivity of $d_{d}$ or $S_{\text {crit }}$ on $N_{\text {ion }}$ or $\sigma_{s}$. Sensitivities were determined for both model substances for data on dry diameters of 50,75, 100, and 125 $\mathrm{nm}$. The compiled results are shown in Fig. 7. The gradients of the curves for a lowering of $\sigma_{s}$ compared to a lowering of $N_{\text {ion }}$ were opposite. Therefore, to facilitate a comparison of the results, Fig. 7 gives the absolute values of the derived sensitivities. These values are given separately in different panels for the different dry diameters. Each panel shows values for both model substances. The sensitivities are given depending on the saturation and, as separate points, for $S_{\text {crit }}$.

The sensitivities shown in Fig. 7 can be used to estimate deviations in $d_{d}$ or $S_{\text {crit }}$ due to uncertainties in $N_{\text {ion }}$ or $\sigma_{s}$, assuming that

$$
\Delta f=\frac{\partial f}{\partial x} \Delta x \approx \frac{\Delta f}{\Delta x_{1 \%}} \Delta x,
$$




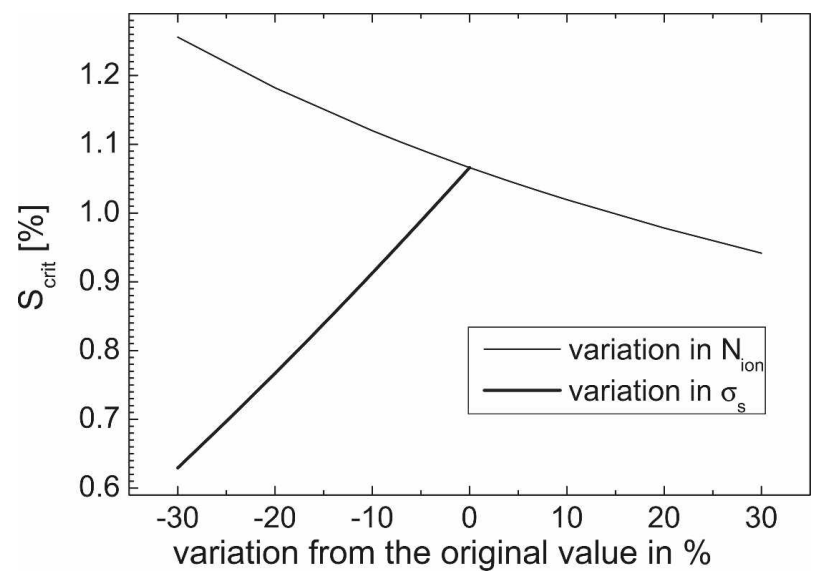

FIG. 6. Values of $S_{\text {crit }}$ for both variations of $\sigma_{s}$ for a constant $a_{w}$ and variations of $N_{\text {ion }}$ for a constant $K$ for particles with a dry diameter of $50 \mathrm{~nm}$ (consisting of the less hygroscopic model substance).

with $f=d_{d}$ or $S_{\text {crit }}$ and $x=N_{\text {ion }}$ or $\sigma_{s}$. For example, for a 50-nm particle of the less soluble substance, the sensitivity of $S_{\text {crit }}$ to $\sigma_{s}$, taken from the upper left of Fig. 7, is

$$
\frac{\Delta S_{\text {crit }}}{\Delta \sigma_{s}} \approx 0.0145
$$

From this it can be derived that a $10 \%$ change in $\sigma_{s}$ (from 72.8 to $65.5 \mathrm{mN} \mathrm{m}^{-1}$ ) results in $\Delta S_{\text {crit }}=0.0145 \times$ $10 \%=0.145 \%$ - that is, $S_{\text {crit }}$ for the 50 -nm particle consisting of the less soluble substance is lowered from $1.07 \%$ to $0.925 \%$.

A striking feature of Fig. 7 is the similarity of the shape of the curves in the different panels. Looking at the hygroscopic growth regime, the sensitivity of $d_{d}$ increases in general toward larger saturations. Also within the hygroscopic growth regime and for all dry diameters, the more hygroscopic substance is in general more sensitive than the less hygroscopic substance. This is different for the sensitivity of $S_{\text {crit }}$ to either $\sigma_{s}$ or $N_{\text {ion }}$, which is larger for the less hygroscopic substance than for the more hygroscopic one. For both substances and at all dry diameters, the hygroscopic growth up to a saturation of 0.99 is more sensitive to $N_{\text {ion }}$ than to $\sigma_{s}$. This is different at saturations above 0.99 and at $S_{\text {crit }}$, where the sensitivity to $\sigma_{s}$ exceeds that to $N_{\text {ion }}$. Indeed, the sensitivity to $\sigma_{s}$ is very low for saturations below 0.95 and increases rapidly above that saturation, being about twice as much than that to $N_{\text {ion }}$ at activation.

In addition to the described similarities for the different dry diameters, there are also differences. These are the absolute values of the sensitivities, which differ in the different panels. For an increasing dry diameter, the same variation in either $\sigma_{s}$ or $N_{\text {ion }}$ causes a larger shift in $d_{d}$ than in $S_{\text {crit }}$.

Summarizing, the following most important conclusions can be drawn from the sensitivities depicted in Fig. 7:

(i) the hygroscopic growth regime (i.e., $d_{d}$ ) is more sensitive to variations of $N_{\text {ion }}$ than to variations in $\sigma_{s}$

(ii) whereas the hygroscopic growth below saturations of 0.95 is almost insensitive to $\sigma_{s}$, its sensitivity to $\sigma_{s}$ becomes important at larger saturations;

(iii) $S_{\text {crit }}$ is about twice as sensitive to a variation of $\sigma_{s}$ than to a similar variation of $N_{\text {ion }}$;

(iv) in the hygroscopic growth regime, the more hygroscopic substance is more sensitive than the less hygroscopic one, with an increasing sensitivity toward larger dry diameters; and

(v) $S_{\text {crit }}$ of less hygroscopic substances is more sensitive than that of the more hygroscopic ones, with an increasing sensitivity toward lower dry diameters.

\section{Cases with concentration-dependent $\sigma_{s}$}

The main result from the examinations described above is that the sensitivity to $\sigma_{s}$ is very low for saturations below 0.95 , whereas $S_{\text {crit }}$ is more sensitive to a variation in $\sigma_{s}$ than to a variation of the same magnitude in $N_{\text {ion }}$.

This result was obtained by using a constant value of $\sigma_{s}$. However, $\sigma_{s}$ may depend on the concentration of the solution (Szyszkowski 1908; ZW08). In the following, results from the Köhler equation using $\sigma_{s}$ as given in Fig. 3 are compared to those using the value of $\sigma$ for water. In the calculations, $N_{\text {ion }}$ is taken from values given in Table 1.

The upper panel of Fig. 8 shows the modeled hygroscopic growth of HULIS particles, first using the $\sigma$ of water (water case) and then using values for $\sigma_{s}$ as given in Fig. 3 (HULIS1 and HULIS2, based on a parameterization of measurements done by ZW08). Calculations were done for $d_{\text {dry }}=100 \mathrm{~nm}$. The lower panel of Fig. 3 gives the difference between either HULIS1 or HULIS2 and the measured equilibrium diameter of the water case. This difference amounts to less than $5 \mathrm{~nm}$ over the whole range up to $99.5 \% \mathrm{RH}$ when using the $\sigma_{s}$ of HULIS1, whereas it is below $5 \mathrm{~nm}$ for up to $98 \%$ $\mathrm{RH}$ and rises to $12 \mathrm{~nm}$ at $99.5 \% \mathrm{RH}$ for the $\sigma_{s}$ of HULIS2. This difference decreases for smaller $d_{\text {dry }}$ (see sensitivities in Fig. 7) and can be considered small.

Figure 9 gives values of $S_{\text {crit }}$ calculated for the same conditions as above for a $d_{\text {dry }}$ of $50,75,100$, and $125 \mathrm{~nm}$, respectively. For 50-nm particles, the difference in $S_{\text {crit }}$ 

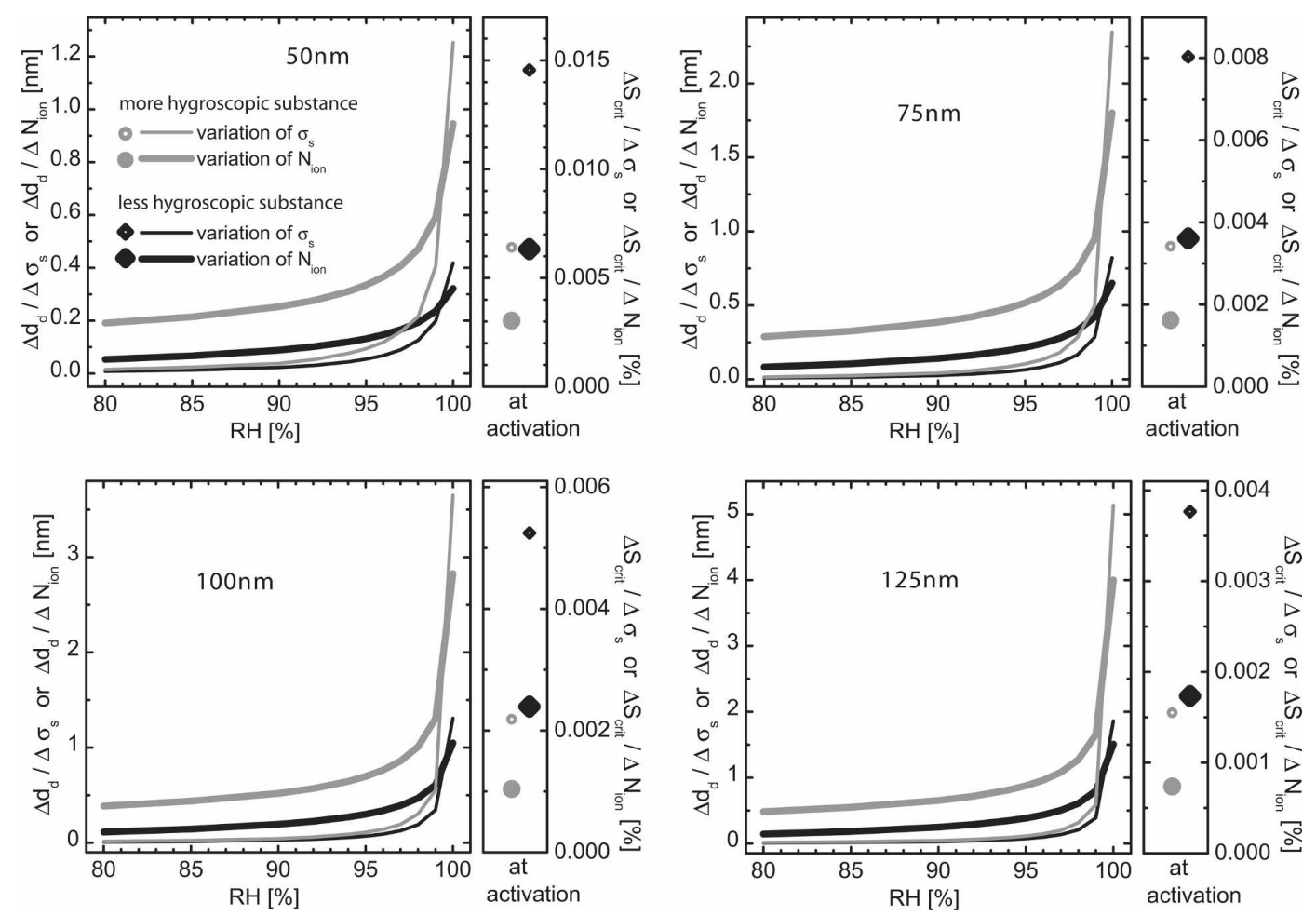

FIG. 7. The sensitivities of $d_{d}$ and $S_{\text {crit }}$ to variations in $\sigma_{s}$ or $N_{\text {ion }}$ for both model substances, with results for different $d_{\mathrm{dry}}$, from 50 to $125 \mathrm{~nm}$.

between the water case and HULIS1 is $0.1 \%$; it is $0.2 \%$ (absolute in $S$ ) between the water case and HULIS2. As shown above, the influence of $\sigma_{s}$ on $S_{\text {crit }}$ decreases (in absolute numbers) as $d_{\mathrm{dry}}$ increases. Figures 8 and 9 show that $\sigma_{s}$ does have an influence on $S_{\text {crit }}$, but it hardly influences hygroscopic growth. It also becomes

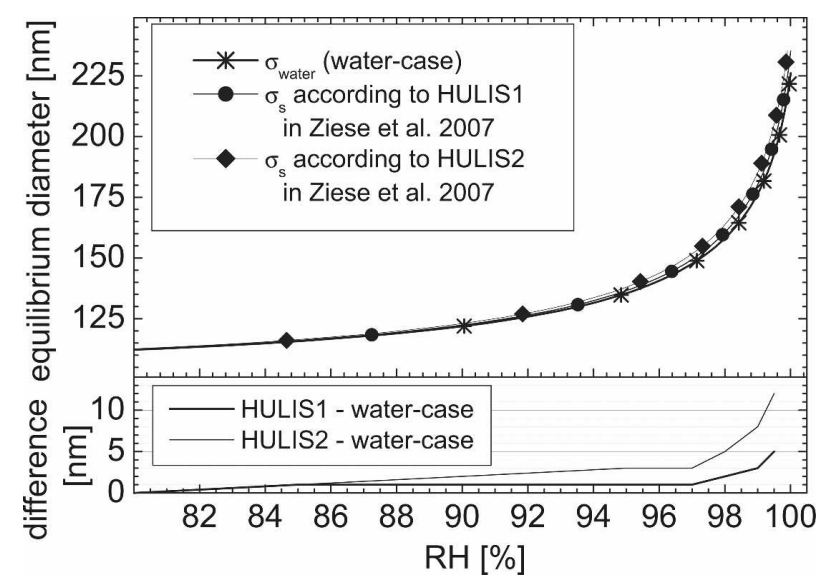

FIG. 8. (top) Modeled hygroscopic growth for HULIS particles with $d_{\mathrm{dry}}=100 \mathrm{~nm}$, first using the $\sigma$ of water (water case) and then using values for $\sigma_{s}$ as given in Fig. 3 (HULIS1 and HULIS2). (bottom) The difference between the measured equilibrium diameter of the water case and HULIS1 or HULIS2, respectively, in $\mathrm{nm}$. clear that this influence of $\sigma_{s}$ on $S_{\text {crit }}$ is mainly important for particles with small $d_{\mathrm{dry}}$ in the range below $100 \mathrm{~nm}$.

From the sensitivities given in Fig. 7 it follows that for $d_{\text {dry }}$ of $50 \mathrm{~nm}$ a variation of $1 \%$ in $\sigma_{s}$ was found to causes a shift in $S_{\text {crit }}$ of $0.0145 \%$ (absolute in $S$ ) for the less hygroscopic substance. Figure 3 gives $\sigma_{s}$ values of 68 and $64 \mathrm{mN} \mathrm{m}^{-1}$ for HULIS1 and HULIS2, respec-

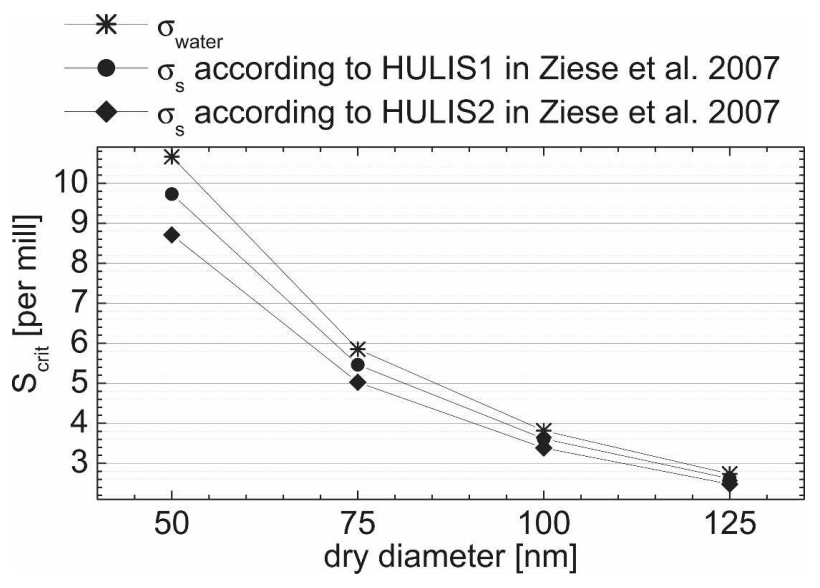

FIG. 9. Values of $S_{\text {crit }}$ at different dry particle sizes using either $\sigma$ of water or the concentration-dependent values of $\sigma_{s}$ from ZW08. 
tively, at the point of activation for particles with a dry diameter of $50 \mathrm{~nm}$ [i.e., a shift toward the $\sigma$ of water of $5 \mathrm{mN} \mathrm{m}^{-1}$ (or $7 \%$ ) and $9 \mathrm{mN} \mathrm{m}^{-1}$ (or $12 \%$ )]. Thus, from the sensitivity of $\sigma_{s}$ to $S_{\text {crit }}$ there follows a shift in $S_{\text {crit }}$ of $0.1 \%$ and $0.2 \%$, respectively. These shifts are similar to those derived from calculations with the Köhler equation and a concentration-dependent $\sigma_{s}$. This corroborates the possibility of using the sensitivities derived in section 5 (Fig. 7) to derive deviations in $d_{d}$ or $S_{\text {crit }}$ caused by deviations in $N_{\text {ion }}$ or $\sigma_{s}$.

\section{Considerations for the inclusion of partitioning}

Calculations of the equilibrium composition using all variations of Köhler theory have in the past assumed that the total solute concentrations define both $a_{w}$ and $\sigma_{s}$. In essence, the Raoult and Kelvin terms are assumed to be "uncoupled." This assumption was employed in the previous sections that used the fundamental Köhler equation. However, an alteration of $\sigma_{s}$ can be caused by changing concentration gradients approaching the surface. Small concentrations of organic material may significantly affect the mixture surface tension (Poling et al. 2001). Here, the hydrocarbon portion of the molecule behaves like a hydrophobic material and tends to be rejected from the water phase by preferentially concentrating on the surface (Poling et al. 2001). In such a case, the bulk concentration can be very different from the surface concentration, affecting both the Raoult and the Kelvin terms simultaneously. In Gibbs surface thermodynamics, the surface phase between the homogeneous liquid and vapor phase is taken to be infinitely thin, allowing an exact definition of the droplet radius (Sorjamaa and Laaksonen 2006). Thus, technically one should account for altered concentrations in the bulk and a surface layer:

$$
n_{i}^{t}=n_{i}^{b}+n_{i}^{s}
$$

where $n_{i}^{t}$ is the total amount of the component $i$ and $n_{i}^{b}$ and $n_{i}^{s}$ are the bulk and surface phase concentrations, respectively. Recently, the neglect of bulk to surface phase partitioning has been investigated in various studies (e.g., Sorjamaa and Laaksonen 2006; Kokkola et al. 2006; Topping et al. 2007). Briefly, calculating the distribution between the bulk and surface phase relies on the ability to solve the Gibbs adsorption isotherm Eq. (12) and thus treat the gradient of $\sigma_{s}$ with changing composition. The Gibbs adsorption equation relates the change in surface energy to changes in thermodynamic variables and excess quantities:

$$
\sum_{i} n_{i}^{s} d \mu_{i}+A_{\mathrm{drop}} d \sigma_{s}=0,
$$

where $\mu_{i}$ is the chemical potential of component $i, A_{\text {drop }}$ is the surface area of the droplet, and $\sigma_{s}$ is the surface tension of the solution. Dividing Eq. (12) by the surface area of the droplet, one arrives at

$$
\sum_{i} \Gamma_{i}^{s} d \mu_{i}+d \sigma_{s}=0
$$

where $\Gamma_{i}^{s}$ is the surface excess of component $i$ (mol $\mathrm{m}^{-2}$ ). The size of the droplet is important because as the surface to volume ratio increases, the depletion of material from the bulk becomes important for thermodynamic properties (Sorjamaa and Laaksonen 2006). In this study, the effect of uncertainty in the surface tension characteristic of a given compound on bulk to surface partitioning is briefly explored. To capture these uncertainties, the Szyszkowski equation is used with parameters fit to recent experimental data for fulvic acid (Topping et al. 2007), a common proxy for humiclike material in the atmosphere. The Szyszkowski equation can be written as

$$
\sigma_{s}=\sigma_{w}-a T\left[\log _{10}(1+b x)\right],
$$

where $\sigma_{s}$ again is the surface tension of the solution, $\sigma_{w}$ is the surface tension of pure water, and $x$ is the solute mole fraction. For this study the parameter $a=0.06473$ $\mathrm{N} \mathrm{m}^{-1} \mathrm{~K}^{-1}$ and $b=45586.87346$ (Topping et al. 2007).

A solution to the Gibbs adsorption equation [Eq. (12)] was found by varying the concentration of solute molecules in the bulk using the numerical technique as described by Sorjamaa and Laaksonen (2006). To use this method and reduce our unknowns down to one, we first assumed that the surface excess of water is zero, following $\mathrm{Li}$ et al. (1998). The gradient of surface tension is found by employing the Szyskowski equation, and activity gradients were calculated using the original universal functional activity coefficient (UNIFAC) framework and the parameters of Hansen et al. (1991).

Before the subsequent differences between the results for cases considering and omitting partitioning are analyzed, Fig. 10 shows the variation in the calculated surface excess concentration for fulvic acid as a function of wet size for particles with an initial dry diameter of 100 and $200 \mathrm{~nm}$. Also shown are the surface tensions that result for the cases in which partitioning was and was not taken into account. The excess values for the case omitting partitioning equal the values of the concentrated partitioning case, and the change in $\sigma_{s}$ for the nonpartitioning case only originates in the change in the droplet solution concentration.

What is the impact of the above on the associated Köhler curves? Figure 11 shows the predicted Köhler curves for both a partitioning and nonpartitioning case study for both a 100- and a 200-nm dry diameter particle. The surface tension is also plotted. This figure clearly shows that consideration of bulk to surface par- 


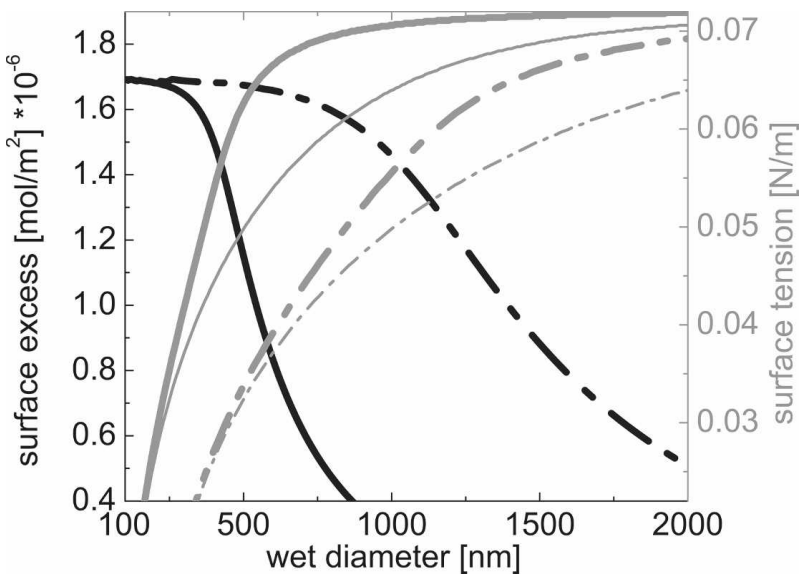

FIG. 10. Surface excess concentrations vs wet diameter for a fulvic acid particle (black; left axis) with an initial dry diameter of 100 (solid line) or $200 \mathrm{~nm}$ (dashed-dotted line). Also shown are the corresponding surface tensions (gray; right axis) for both the partitioning and the nonpartitioning case (thick and thin gray lines, respectively).

titioning increases the critical saturation ratio. This increase has to be attributed to both the increase in $\sigma_{s}$ and the change in the amount of soluble substance in solution. For the particles with a dry diameter with 100 $\mathrm{nm}$, the values of $S_{\text {crit }}$ for the partitioning and the nonpartitioning case are $0.38 \%$ and $0.27 \%$, whereas $\sigma_{s}$ at the point of activation is 56 and $46 \mathrm{mN} \mathrm{m}^{-1}$, respectively (see Fig. 11). This is a difference of $19 \%$ between the values for $\sigma_{s}$ for the two cases. When looking at the results presented in Fig. 7, this increase in $\sigma_{s}$ would be expected to amount to an increase in $S_{\text {crit }}$ of $0.099 \%$ (absolute)-a $0.0052 \%$ change in $S_{\text {crit }}$ per $1 \%$ change in $\sigma_{s}$ for a $100-\mathrm{nm}$ particle of the less soluble substance.

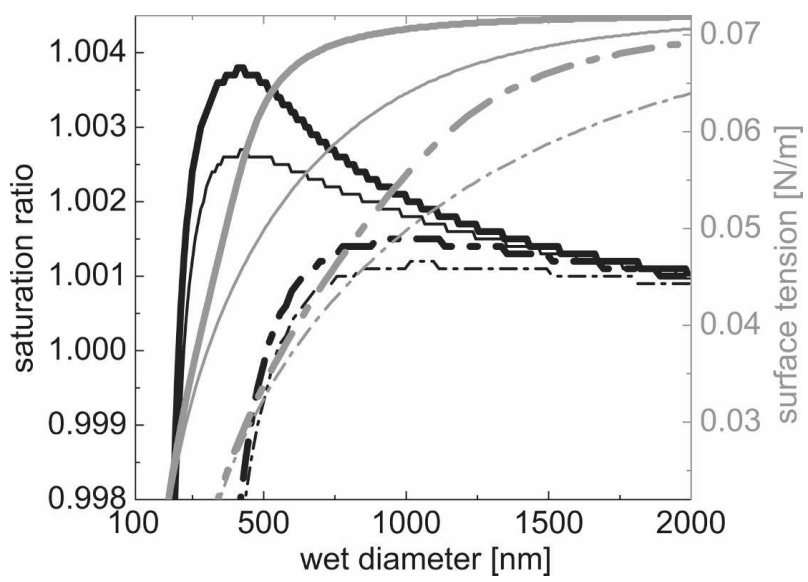

FIG. 11. Koehler curves (black) for a fulvic acid particle with an initial dry diameter of 100 (solid lines) or $200 \mathrm{~nm}$ (dashed-dotted lines) for the partitioning (thick lines) and the nonpartitioning (thin lines) cases. Also shown, in gray, are the corresponding surface tensions from Fig. 10.
Thus, the increase in $S_{\text {crit }}$ between the partitioning and the nonpartitioning case is slightly larger $(0.11 \%$ absolute) than one that would originate only from a change of $\sigma_{s}$ because of the additional change in the amount of soluble substance in solution. However, the change in $\sigma_{s}$ explains most of the increase of $S_{\text {crit }}$ between the partitioning and the nonpartitioning case.

This shows that partitioning changes both the $\sigma_{s}$ of the droplets and the solution concentration, with $\sigma_{s}$ being the more influential parameter.

\section{Consequences}

The above demonstrated sensitivities of $d_{d}$ and of $S_{\text {crit }}$ on variations in $N_{\text {ion }}$ and $\sigma_{s}$ have some practical consequences.

Deriving $S_{\text {crit }}$ from measurements of the hygroscopic growth is only possible if the examined substance has no influence on $\sigma_{s}$. Information about $\sigma_{s}$ simply cannot be drawn from measurements on the hygroscopic growth because hygroscopic growth (i.e., $d_{d}$ ) is not sensitive to $\sigma_{s}$, especially at saturations below 0.95 . Fitting the Köhler equation to measurements of the hygroscopic growth and deriving $S_{\text {crit }}$ from this fitted equation will lead to wrong values of $S_{\text {crit }}$ if the wrong $\sigma_{s}$ is used. Obtaining a correct value for $\sigma_{s}$, however, and correctly describing possible influences of partitioning (which also can effect $S_{\text {crit }}$ ) are both difficult.

The sensitivity of $S_{\text {crit }}$ to $\sigma_{s}$ and to the correct description of partitioning increases as the particle size decreases and is especially important in the diameter range below $100 \mathrm{~nm}$. A $10 \%$ shift in $\sigma_{s}$ (from 72.8 to $65.5 \mathrm{mN} \mathrm{m}^{-1}$ ) causes a decrease in $S_{\text {crit }}$ for the less hygroscopic substance of about $0.15 \%, 0.08 \%$, and $0.05 \%$ for particles with dry diameters of 50,75 , and 100 $\mathrm{nm}$, respectively, the shift for the latter being at about the measurement accuracy for measurements of $S_{\text {crit }}$. Whereas for the larger particles the sensitivity of $S_{\text {crit }}$ to $\sigma_{s}$ cannot be resolved by up-to-date measurement techniques, this sensitivity is important and can be resolved for particles below $100 \mathrm{~nm}$, the size range at which atmospheric aerosol particles under atmospheric conditions do or do not activate (Dusek et al. 2006). Thus, omitting an effect of particle chemical composition on $\sigma_{s}$ can lead to erroneous predictions of the particle activation behavior.

A simple sensitivity study was performed, estimating the change in the number of activated droplets $\left(N_{\text {act }}\right)$ for a $10 \%$ change in $\sigma_{s}$ from 72.8 to $65.5 \mathrm{mN} \mathrm{m}^{-1}$. The estimates were based on atmospheric aerosol number size distributions measured at an urban location during the Lindenberg Aerosol Characterization Experiment (LACE 98; Wex et al. 2002) and at a rural background station [the Leibniz Institute for Tropospheric Re- 


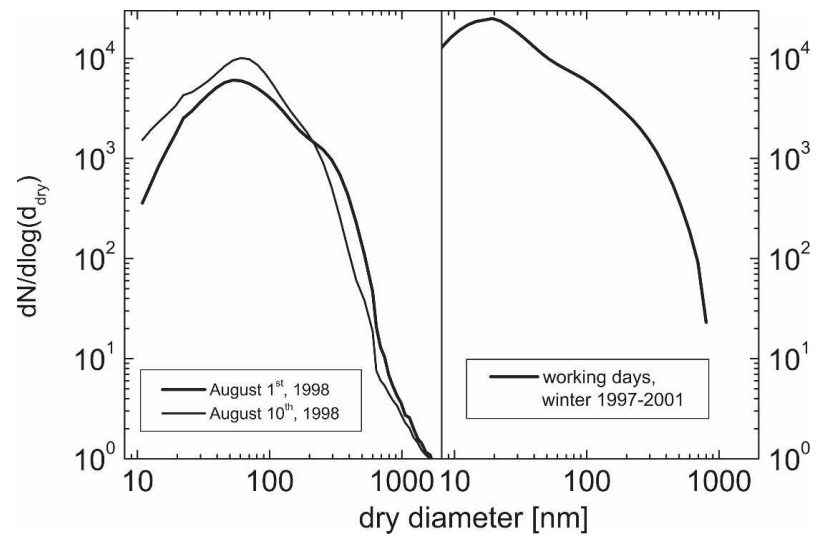

FIG. 12. Atmospheric particle number size distributions measured at (left) a rural location during LACE 98 (Wex et al. 2002) and (right) a rural background station (IfT; Tuch et al. 2003).

search (IfT), Leipzig, Germany; Tuch et al. 2003]; see Fig. 12. The data taken from LACE 98 had been measured with a time resolution of $15 \mathrm{~min}$ and were averaged over 1 day for each of the two distributions used in this study. Data taken from Tuch et al. (2003) were average number size distributions measured on working days in winter over several years (1997-2001).

For a fixed supersaturation, the critical diameter for the activation $d_{\text {crit }}$ was determined, once using $\sigma$ of water $\left(72.8 \mathrm{mN} \mathrm{m}^{-1}\right)$ and again using $\sigma_{s}=65.5 \mathrm{mN} \mathrm{m}^{-1}$; $N_{\text {act }}$ was determined as the integral of the measured number size distribution above that diameter $\left(N_{\mathrm{act}}^{\prime}\right.$ for $\sigma_{s}=72.8 \mathrm{mN} \mathrm{m}^{-1}$ and $N_{\text {act }}^{\prime \prime}$ for $\sigma_{s}=65.5 \mathrm{mN} \mathrm{m}^{-1}$ ). This is illustrated in Fig. 13. The detailed parameters with which this study was performed are given in Table 2 . The relative increase in $N_{\text {act }}$ is given in Table 2 as

$$
F=\left(N_{\text {act }}^{\prime \prime}-N_{\text {act }}^{\prime}\right) / N_{\text {act }}^{\prime} \text {. }
$$

Two extreme cases were considered in which all particles were assumed to be chemically equal to either the more or the less hygroscopic substance used in this study, respectively. Also, two dry particle sizes were considered; that is, the supersaturations were chosen such that for $\sigma_{s}=72.8 \mathrm{mN} \mathrm{m}^{-1}, d_{\text {crit }}$ was $125 \mathrm{~nm}$ in one case and $50 \mathrm{~nm}$ in the second case. The examined lowering of $\sigma_{s}$ caused a lowering of $d_{\text {crit }}$ from 125 to 112.5 $\mathrm{nm}$ and from 50 to $45 \mathrm{~nm}$, independent of the substance.

The value of $F$ for the three different number size distributions was found to be about $21 \%$ at the larger $d_{\text {crit }}$ and about $10 \%$ for the lower $d_{\text {crit }}$. This implies that, independent of the chemical composition of the particles, an influence of the chemical composition on the surface tension has to be accounted for to derive the correct numbers of activated particles.

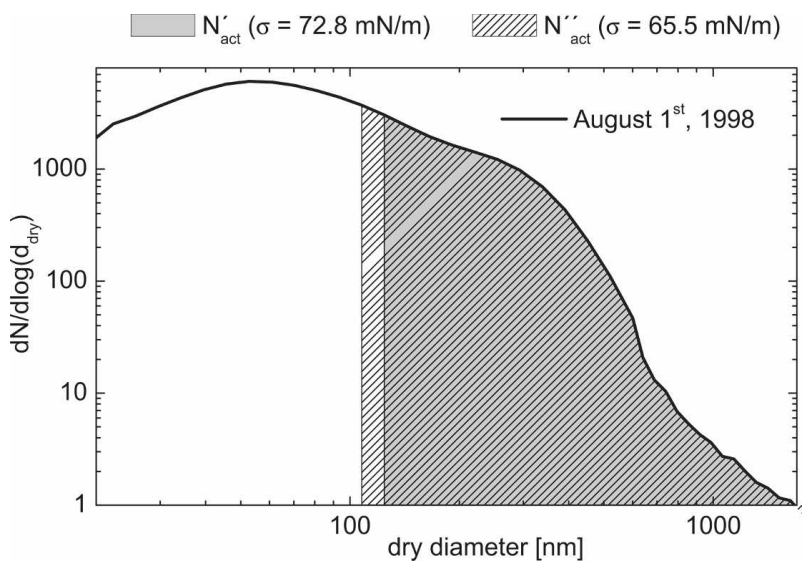

FIG. 13. Particles activated to droplets for an identical $S_{\text {crit }}$ when either $\sigma_{s}=72.8 \mathrm{mN} \mathrm{m}^{-1}$ (gray area; $N_{\text {act }}^{\prime}, d_{\text {crit }}=125 \mathrm{~nm}$ ) or $\sigma_{s}=$ $65.5 \mathrm{mN} \mathrm{m}^{-1}$ (hatched area; $N_{\text {act }}^{\prime \prime}, d_{\text {crit }}=112.5 \mathrm{~nm}$ ) is used to derive $d_{\text {crit }}$.

Values for $F$ derived here exceed a comparable estimation made by Facchini et al. (1999), where a simplified relationship between the number of cloud droplets $N$ and $S_{\text {crit }}$ was used $\left(N \propto S_{\text {crit }}^{0.5}\right)$. Facchini et al. (1999) concluded that a $30 \%$ decrease in $\sigma_{s}$ results in a $20 \%$ increase in $N$. The stronger effect found in our work arises from the fact that measured number size distributions were used instead of an approximation, and our results hint to an even larger effect of surface tension reduction on $N$. This should be tested by implementing the sensitivities derived in this study with cloud parcel models, a task that is beyond the scope of the study presented here.

\section{Conclusions}

In this study, the sensitivity of hygroscopic growth and activation as modeled with the Köhler equation was examined. Values of the parameters which are used in the Köhler equation were varied to simulate an uncertainty in these values. The extent of the variations was chosen according to the range of uncertainties which exist for the respective parameters in up-to-date knowledge - that is, uncertainties in the surface tension $\sigma_{s}$, which was varied from $72.8 \mathrm{mN} \mathrm{m}^{-1}$ (water) down to $51 \mathrm{mN} \mathrm{m}^{-1}$ (following values reported in literature, e.g., Facchini et al. 1999; Salma et al. 2006; Kiss et al. 2005), and uncertainties which may arise from ideal treatment of nonideal solutions, a lack of knowledge of the density and molecular weight of the substances dissolved in a droplet, or uncertainties in the dry particle diameter. The examined dry particle sizes were in the range in which atmospheric particles may activate (i.e., from 50 to $125 \mathrm{~nm}$ ). 
TABLE 2. Values of parameters as used when determining the change in the number of activated droplets on a change in $\sigma_{s}$.

\begin{tabular}{|c|c|c|c|c|c|c|}
\hline & \multirow[b]{2}{*}{$S_{\text {crit }}$} & \multirow[b]{2}{*}{$d_{\text {crit }}$ for $\sigma_{s}=72.8 \mathrm{mN} \mathrm{m}^{-1}$} & \multirow[b]{2}{*}{$d_{\text {crit }}$ for $\sigma_{s}=65.5 \mathrm{mN} \mathrm{m}^{-1}$} & \multicolumn{3}{|c|}{$F$ for number size distribution of } \\
\hline & & & & 1 Aug 1998 & 10 Aug 1998 & Winter 1997-2001 \\
\hline More hygroscopic & $0.11 \%$ & $125 \mathrm{~nm}$ & $112.5 \mathrm{~nm}$ & $20 \%$ & $27 \%$ & $16 \%$ \\
\hline Less hygroscopic & $0.27 \%$ & & & & & \\
\hline More hygroscopic & $0.45 \%$ & $50 \mathrm{~nm}$ & $45 \mathrm{~nm}$ & $9 \%$ & $9 \%$ & $11 \%$ \\
\hline Less hygroscopic & $1.07 \%$ & & & & & \\
\hline
\end{tabular}

It was found that the examined variations cause significant changes in both hygroscopic growth and activation. The major insight is that although the hygroscopic growth regime below $95 \% \mathrm{RH}$ is insensitive toward $\sigma_{s}$, nonetheless $\sigma_{s}$ has a large influence on the activation, and increasingly so for decreasing particle size.

When taking into account a change in $\sigma_{s}$ with droplet concentration, the sensitivities derived in this work were shown to be applicable to deriving the change in activation due to the change in $\sigma_{s}$. However, it also became obvious that knowledge of the value of $\sigma_{s}$ at the point of activation is important.

This was found again when taking into account partitioning of the surface active compound in the particle. For this case, the changing droplet concentration also influences the activation, but to a smaller extend. However, partitioning is important to account for because it influences $\sigma_{s}$, yielding values of $\sigma_{s}$ that are above those that are obtained when omitting partitioning.

The dependence of the activation on $\sigma_{s}$ implies that a CCN closure, connecting particle hygroscopic growth to activation, cannot be successful if the examined substance has an influence on $\sigma_{s}$ that is ignored, especially for smaller particles in the size range from 50 to $100 \mathrm{~nm}$, which is important for cloud droplet activation in the atmosphere.

Based on measured atmospheric particle number size distributions, it was estimated that a lowering of $\sigma_{s}$ by only $10 \%$ causes a change in the activated fraction (i.e., in the cloud droplet number concentration) of $10 \%$ to $20 \%$. This change is large enough to cause a noticeable influence on the radiation budget of a corresponding cloud, leading to erroneous estimates of cloud radiation budgets.

It becomes obvious that the surface tension is an important factor when determining the activation of aerosol particles to cloud droplets. Examining the effective surface tensions of growing particles/droplets during the activation process is an important field in which research will have to be performed in the future.

\section{REFERENCES}

Albrecht, B. A., 1989: Aerosols, cloud microphysics, and fractional cloudiness. Science, 245, 1227-1230.
Brechtel, F. J., and S. M. Kreidenweis, 2000a: Predicting particle critical supersaturation from hygroscopic growth measurements in the humidified TDMA. Part I: Theory and sensitivity studies. J. Atmos. Sci., 57, 1854-1871.

- and $-2000 \mathrm{~b}$ : Predicting particle critical supersaturation from hygroscopic growth measurements in the humidified TDMA. Part II: Laboratory and ambient studies. J. Atmos. Sci., 57, 1872-1887.

Broekhuizen, K., R. Y.-W. Chang, W. R. Leaitch, S.-M. Li, and J. P. D. Abbatt, 2006: Closure between measured and modeled cloud condensation nuclei (CCN) using size-resolved aerosol composition in downtown Toronto. Atmos. Chem. Phys., 6, 2513-2524.

Chang, R. Y.-W., P. S. K. Liu, W. R. Leaitch, and J. P. D. Abbatt, 2007: Comparison between measured and predicted CCN concentrations at Egbert, Ontario: Focus on the organic aerosol fraction at a semi-rural site. Atmos. Environ., 41, 81728182.

Covert, D. S., J. L. Gras, A. Wiedensohler, and F. Stratmann, 1998: Comparison of directly measured CCN with CCN modeled from the number-size distribution in the marine boundary layer during ACE 1 at Cape Grim, Tasmania. J. Geophys. Res., 103, 16 597-16 608.

Dinar, E., T.F. Mentel, and Y. Rudich, 2006a: The density of humic acids and humic like substances (HULIS) from fresh and aged wood burning and pollution aerosol particles. Atmos. Chem. Phys., 6, 5213-5224.

—, I. Taraniuk, E. R. Graber, S. Katsman, T. Moise, T. Anttila, T. F. Mentel, and Y. Rudich, 2006b: Cloud condensation nuclei properties of model and atmospheric HULIS. Atmos. Chem. Phys., 6, 2465-2481.

Dusek, U., D. S. Covert, A. Wiedensohler, C. Neusü $\beta$, D. Weise, and W. Chantrell, 2003: Cloud condensation nuclei spectra derived from size distributions and hygroscopic properties of the aerosol in coastal southwest Portugal during ACE-2. Tellus, 55B, 35-53.

— cloud-nucleating ability of aerosol particles. Science, 312, 1375-1378.

Ervens, B., M. Cubison, E. Andrews, G. Feingold, J. A. Ogren, J. L. Jimenez, P. DeCarlo, and A. Nenes, 2007: Prediction of cloud condensation nucleus number concentration using measurements of aerosol size distributions and composition and light scattering enhancement due to humidity. J. Geophys. Res., 112, D10S32, doi:10.1029/2006JD007426.

Facchini, M., M. Mircea, S. Fuzzi, and R. J. Charlson, 1999: Cloud albedo enhancement by surface-active organic solutes in growing droplets. Nature, 401, 257-259.

— S. Decesari, M. Mircea, S. Fuzzi, and G. Loglio, 2000: Surface tension of atmospheric wet aerosol and cloud/fog droplets in relation to their organic carbon content and chemical composition. Atmos. Environ., 34, 4853-4857.

Forster, P., and Coauthors, 2007: Changes in atmospheric con- 
stituents and in radiative forcing. Climate Change 2007: The Physical Science Basis. S. Solomon et al., Eds., Cambridge University Press, 129-234.

Hansen, H. K., P. Rasmussen, A. Fredenslund, M. Schiller, and J. Gmehling, 1991: Vapor-liquid equilibria by Unifac group contribution. 5. Revision and extension. Ind. Eng. Chem. Res., 30 (10), 2352-2355.

Henning, S., T. Rosenorn, B. D'Anna, A. A. Gola, B. Svenningsson, and M. Bilde, 2005: Cloud droplet activation and surface tension of mixtures of slightly soluble organics and inorganic salt. Atmos. Chem. Phys., 5, 575-582.

Hoffer, A., A. Gelencser, P. Guyon, G. Kiss, O. Schmid, G. P. Frank, P. Artaxo, and M. O. Andreae, 2006: Optical properties of humic-like substances (HULIS) in biomass-burning aerosols. Atmos. Chem. Phys., 6, 3563-3570.

Kiss, G., E. Tombacz, B. Varga, T. Alsberg, and L. Persson, 2003: Estimation of the average molecular weight of humic-like substances isolated from fine atmospheric aerosol. Atmos. Environ., 37, 3783-3794.

- - - and H. C. Hansson, 2005: Surface tension effects of humic-like substances in the aqueous extract of tropospheric fine aerosol. J. Atmos. Chem., 50, 279-294.

Koehler, K. A., S. M. Kreidenweis, P. J. DeMott, A. J. Prenni, C. M. Carrico, B. Ervens, and G. Feingold, 2006: Water activity and activation diameters from hygroscopicity data. Part II: Application to organic species. Atmos. Chem. Phys., 6, 795-809.

Kokkola, H., R. Sorjamaa, A. Peräniemi, T. Raatikainen, and A. Laaksonen, 2006: Cloud formation of particles containing humic-like substances. Geophys. Res. Lett., 33, L10816, doi:10.1029/2006GL026107.

Kreidenweis, S. M., K. A. Koehler, P. DeMott, A. J. Prenni, C. M. Carrico, and B. Ervens, 2005: Water activity and activation diameters from hygroscopicity data. Part I: Theory and application to inorganic salts. Atmos. Chem. Phys., 5, 13571370.

Li, Z., A. L. Williams, and M. J. Rood, 1998: Influence of soluble surfactant properties on the activation of aerosol particles containing inorganic solute. J. Atmos. Sci., 55, 1859-1866.

Low, R. D. H., 1969: A generalized equation for the solution effect in droplet growth. J. Atmos. Sci., 26, 608-611.

McFiggans, G., and Coauthors, 2006: The effect of physical and chemical aerosol properties on warm cloud droplet activation. Atmos. Chem. Phys., 6, 2593-2649.

Poling, B. E., J. M. Prausnitz, and J. P. O'Connell, 2001: The Properties of Gases and Liquids. 5th ed. McGraw-Hill, 768 pp.

Prenni, A. J., M. D. Petters, S. M. Kreidenweis, P. J. DeMott, and P. J. Ziemann, 2007: Cloud droplet activation of secondary organic aerosol. J. Geophys. Res., 112, D10223, doi:10.1029/ 2006JD007963.

Pruppacher, H. R., and J. D. Klett, 1997: Equilibrium between an aqueous salt solution and water vapor. Microphysics of Clouds and Precipitation, Kluwer Academic, 109-115.

Rissler, J., E. Swietlicki, J. Zhou, G. Roberts, M. O. Andreae, G. L. Von, and P. Artaxo, 2004: Physical properties of the sub-micrometer aerosol over the Amazon rain forest during the wet-to-dry season transition-Comparison of modeled and measured CCN concentrations. Atmos. Chem. Phys., 4, 2119-2143.

Salma, I., R. Ocskay, I. Varga, and W. Maenhaut, 2006: Surface tension of atmospheric humic-like substances in connection with relaxation, dilution, and solution pH. J. Geophys. Res., 111, D23205, doi:10.1029/2005JD007015.

Samburova, V., R. Zenobi, and M. Kalberer, 2005: Characterization of high molecular weight compounds in urban atmospheric particles. Atmos. Chem. Phys., 5, 2163-2170.

Sorjamaa, R., and A. Laaksonen, 2006: The influence of surfactant properties on critical supersaturations of cloud condensation nuclei. J. Aerosol Sci., 37, 1730-1736.

, B. Svenningsson, T. Raatikainen, S. Henning, M. Bilde, and A. Laaksonen, 2004: The role of surfactants in Köhler theory reconsidered. Atmos. Chem. Phys., 4, 2107-2117.

Stroud, C. A., and Coauthors, 2007: Cloud activating properties of aerosol observed during CELTIC. J. Atmos. Sci., 64, 441-459.

Svenningsson, B., and Coauthors, 2006: Hygroscopic growth and critical supersaturations for mixed aerosol particles of inorganic and organic compounds of atmospheric relevance. Atmos. Chem. Phys., 6, 1937-1952.

Szyszkowski, B., 1908: Experimentelle Studien über kapillare Eigenschaften der wässrigen Lösungen von Fettsäuren. $Z$. Physik. Chem., 64, 385-414.

Taraniuk, I., E. R. Graber, A. Kostinski, and Y. Rudich, 2007: Surfactant properties of atmospheric and model humic-like substances (HULIS). Geophys. Res. Lett., 34, L16807, doi:10.1029/2007GL029576.

Topping, D. O., G. B. McFiggans, and H. Coe, 2005a: A curved multi-component aerosol hygroscopicity model framework. Part 1: Inorganic compounds. Atmos. Chem. Phys., 5, 12051222.

,-- , and $\longrightarrow, 2005 \mathrm{~b}$ : A curved multi-component aerosol hygroscopicity model framework. Part 2: Including organic compounds. Atmos. Chem. Phys., 5, 1223-1242.

,-- G. Kiss, Z. Varga, M. C. Facchini, S. Decesari, and M. Mircea, 2007: Surface tensions of multi-component mixed inorganic/organic aqueous systems of atmospheric significance: Measurements, model predictions and importance for cloud activation predictions. Atmos. Chem. Phys., 7, 2371-2398.

Tuch, T., B. Wehner, M. Pitz, J. Cyrys, J. Heinrich, W. G. Kreyling, H. E. Wichmann, and A. Wiedensohler, 2003: Longterm measurements of size-segregated ambient aerosol in two German cities located $100 \mathrm{~km}$ apart. Atmos. Environ., 37, $4687-4700$.

Twomey, S., 1974: Pollution and the planetary albedo. Atmos. Environ., 8, 1251-1256.

Wex, H., C. Neusü $\beta$, M. Wendisch, F. Stratmann, C. Koziar, A. Keil, A. Wiedensohler, and M. Ebert, 2002: Particle scattering, backscattering, and absorption coefficients: An in situ closure and sensitivity study. J. Geophys. Res., 107, 8122, doi:10.1029/2000JD000234.

— , and Coauthors, 2007: Hygroscopic growth and measured and modeled critical super-saturations of an atmospheric HULIS sample. Geophys. Res. Lett., 34, L02818, doi:10.1029/ 2006GL028260.

Zhou, J., E. Swietlicki, O. H. Berg, P. P. Aalto, K. Hämeri, E. D. Nilsson, and C. Leck, 2001: Hygroscopic properties of aerosol particles over the central Arctic Ocean during summer. $J$. Geophys. Res., 106, 32 111-32 123.

Ziese, M., H. Wex, E. Nilsson, I. Salma, R. Ocskay, T. Hennig, A. Massling, and F. Stratmann, 2008: Hygroscopic growth and activation of HULIS particles: Experimental data and a new iterative parameterization scheme for complex aerosol particles. Atmos. Chem. Phys., 8, 1855-1866. 